\title{
EKSPLORASI BAHASA RUPA RWD DALAM KOMUNIKASI GRAFIS (Studi Kasus: Karya Mahasiswa Tugas Akhir DKV)
}

\author{
Toto Haryadi ${ }^{1}$, Godham Eko Saputro ${ }^{2}$ \\ 1,2 Program Studi Desain Komunikasi Visual, Fakultas IImu Komputer \\ Universitas Dian Nuswantoro, Jl Imam Bonjol 207 Pendrikan Kidul, Semarang Jawa Tengah \\ Email: ${ }^{1}$ toto.haryadi@dsn.dinus.ac.id, 2godham.eko@gmail.com \\ Received: 2 Agustus 19 \\ Revised: 11 September 2019 \\ Accepted: 18 September 2019
}

\begin{abstract}
Abstrak: Perkembangan media komunikasi saat ini didominasi oleh komunikasi grafis digital yang didukung oleh penggunaan smartphone dan internet, yang banyak diakses oleh generasi milenial. Komunikasi grafis konvensional saat ini masih bertahan untuk segmen anak-anak, yang diaplikasikan pada buku cerita bergambar. Teknik visualisasi buku cerita bergambar cenderung mengadaptasi gaya barat modern yang dikenal dengan 'NPM'. Sampai saat ini penulis hanya menjumpai sedikit buku cerita bergambar, yang dirancang menggunakan bahasa rupa tradisional Indonesia yang dikenal dengan 'RWD', salah satunya yaitu karya Tugas Akhir mahasiswa DKV UDINUS berwujud accordion book. Hal ini menjadi kesempatan bagi penulis untuk mengkaji karya tersebut. Penelitian ini menggunakan metode kualitatif yang diawali dengan peninjauan karya tugas akhir lalu dilanjutkan proses analisis menggunakan pendekatan teori 'wimba' dan 'tata ungkapan'. Hasil dari penelitian ini yaitu penemuan konsep cerita yang terkandung dalam karya accordion book serta cara menerapkan beberapa jenis dan teknik 'wimba' serta 'tata ungkapan' untuk menggambarkan sebuah cerita secara menarik dan unik. Penelitian ini diharapkan bisa memberikan pemahaman bagi praktisi maupun akademisi untuk ikut serta melestarikan bahasa rupa 'RWD' ke dalam proses penciptaan karya desain agar tercipta banyak alternatif dalam visualisasi komunikasi grafis baik konvensional maupun digital.
\end{abstract}

Kata kunci: Bahasa Rupa, DKV, Komunikasi Grafis, NPM, RWD

\begin{abstract}
Currently, the development of communication media is dominated by digital graphic communication which is supported by the usage of smartphones and internet, which are commonly accessed by millennial generation. Conventional graphic communication is still surviving for the children segment, which is applied to the illustration of story books. The visualization technique tends to adapt modern western style which is known as 'NPM'. Thus far, the authors only found few illustrations of story books, which is designed using Indonesia's traditional visual language which is known as 'RWD', one of them is UDINUS student's Final Project in form of accordion book. This is a chance for authors to analyze it. This research uses qualitative method started from reviewing artwork then analyzing it by using 'wimba' and 'tata ungkapan' theories. The result of this research is the story concept contained in accordion book and how to apply
\end{abstract}


several types and techniques of 'wimba' and 'tata ungkapan' to depict a story remarkably and uniquely. This research is expected can be used to share knowledge for designers and academicians to participate in preserving the 'RWD' visual language, into a process of designing artwork in order to create many alternatives in visualization of graphic communication conventionally and digitally.

Keywords: visual language, DKV, graphic communication, NPM, RWD

\section{PENDAHULUAN}

Keterbukaan berbagai ragam informasi dan ilmu pengetahuan membuat manusia semakin mudah dalam menerima pesan-pesan yang disampaikan melalui media. Media komunikasi juga semakin banyak jumlahnya, terutama media massa dan media baru mengalami peningkatan cukup signifikan dan bertransformasi menjadi media digital yang didukung oleh perkembangan industri digital, pertumbuhan smartphone, serta paling utama yaitu jaringan internet (Hariyanto, 2019). Hal ini memberikan banyak alternatif dalam berkomunikasi khususnya komunikasi berbasis visual yang melibatkan peran penting dari sender dan receiver melalui tahapan encoding, messaging (media-noise), decoding, hingga feedback (Kotler dkk dalam Jackson dan Shaw, 2009:158-159).

Posisi sender yang diperankan oleh akademisi maupun praktisi di bidang desain komunikasi visual (DKV) meliputi dosen, mahasiswa, peneliti, hingga praktisi, dituntut untuk mampu mengkomunikasikan gagasan melalui pesan yang efektif dan kreatif, yang sebagian besar diwujudkan dalam bentuk bahasa rupa (encoding). Selain itu, sender juga harus memahami karakteristik receiver atau target audiens agar bisa menentukan media komunikasi yang tepat sasaran sehingga pesannya bisa dipahami dengan jelas (decoding). Berdasarkan hasil survey Nielsen tahun 2017, target audiens dari kelompok milenial (20-34 tahun) memiliki prosentase paling tinggi dalam mengakses media digital berupa televisi sebesar 96\% dan internet sebesar 58\% (Ika, 2018). 
Berdasarkan observasi yang dilakukan penulis, mahasiswa sebagai calon praktisi desain kini cenderung lebih meminati komunikasi grafis di media digital dibanding media konvensional (cetak), mengikuti trend penggunaan media sosial yang cukup masif di kalangan milenial. Adanya perbedaan substansi dan gaya antara komunikasi grafis konvensional dengan komunikasi grafis digital khususnya online menjadi penentu dalam pemilihan media. Media konvensional cenderung lebih rinci dalam menyajikan informasi dan fokus pada kedalaman tajuk cerita, sedangkan media online lebih cocok untuk konten yang singkat dan padat serta mengarah pada penggunaan visual seperti gambar dan ilustrasi untuk mengikat audiens (Kotler, Kartajaya \& Huan, 2017:14). Hal ini bukan berarti media konvensional lebih inferior daripada media digital. Kemampuan media konvensional dalam menampung banyak informasi secara detail memberi kemudahan dibanding media digital yang harus menampilkan konten secara ringkas dan menarik agar tidak kehilangan substansi pesannya.

Meskipun media digital saat ini berkembang dengan sangat pesat, media komunikasi grafis konvensional masih bertahan khususnya yang menyasar segmen usia anak-anak. Masih maraknya buku-buku cerita bergambar (cergam) yang beredar di toko-toko buku dengan banyak peminat menjadi faktor pendukung masih dibutuhkannya media komunikasi grafis konvensional. Sebagai contoh di Provinsi Daerah Istimewa Yogyakarta (DIY) penjualan buku anak terbesar nomor 3 di bawah buku fiksi dan agama. Hal ini didukung adanya komunitas penulis bacaan anak, konsistensi konten buku anak yang cukup terjaga, serta adanya program literasi anak yang dipandu oleh guru maupun orang tua (Cahyana, 2019).

Istilah komunikasi grafis tidak bisa terlepas dari desain grafis dan desain komunikasi visual (DKV). Desain grafis lebih dahulu ada sejak munculnya jurusan seni reklame yang kemudian berkembang, baru beberapa waktu kemudian lahir istilah DKV. Komunikasi grafis ditunjang oleh tiga sub-bidang yaitu: desain grafis, 
ilustrasi, dan fotografi (Oka, 2017:64-66). Dari hal ini bisa dipahami bahwa luaran yang dimanfaatkan untuk komunikasi grafis fokus pada karya desain konvensional yang dicetak pada medium atau bahan tertentu sebagai contoh: komik cetak dan buku cerita bergambar.

Dilihat dari segi visualisasi, buku cerita bergambar yang ada saat ini masih condong pada bahasa rupa barat (modern) yang menangkap dari satu titik, arah, waktu, serta kejadian, yang dikenal dengan istilah Naturalis-Perspektif-Momen opname (NPM). Gambar dalam buku cerita saat ini juga lebih fokus pada hal estetis saja, berbeda dengan konsep bahasa rupa tradisional Indonesia yang lebih menitikberatkan pada aspek komunikasi serta menjadikan gambar sebagai elemen utama dalam sebuah cerita, contohnya lukisan dinding gua prasejarah. Bahasa rupa tradisional Indonesia memiliki teknik penggambaran yang berbeda dengan NPM yakni menangkap dari berbagai titik, arah, waktu, serta kejadian, yang dikenal dengan istilah Ruang-Waktu-Datar (RWD). Bahasa rupa RWD lebih bisa bercerita dibanding NPM.
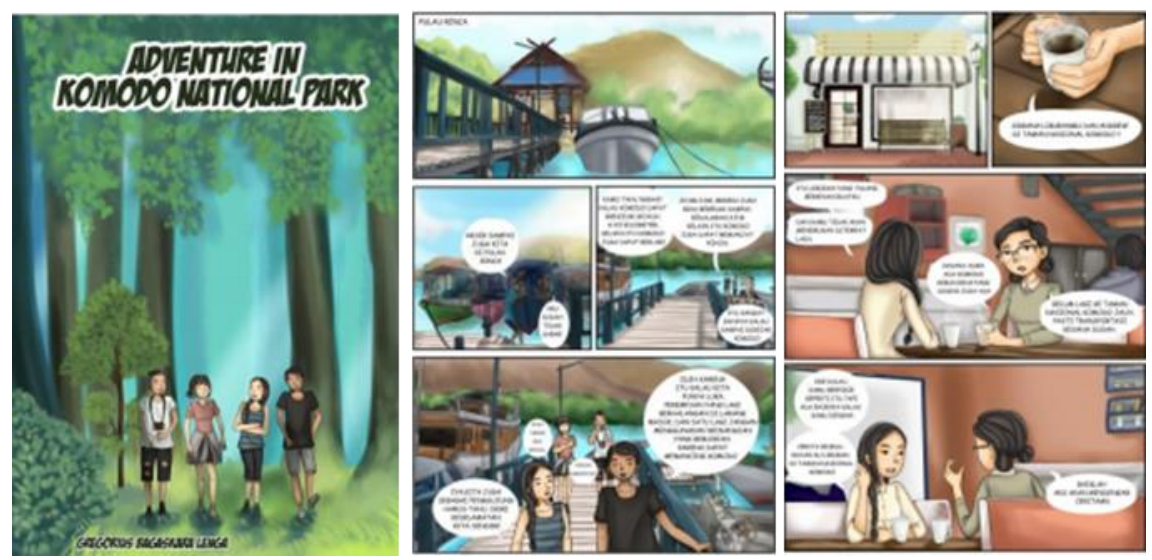

Gambar 1. Komik dengan pendekatan bahasa rupa 'NPM' Sumber: screenshot karya mahasiswa DKV UDINUS 

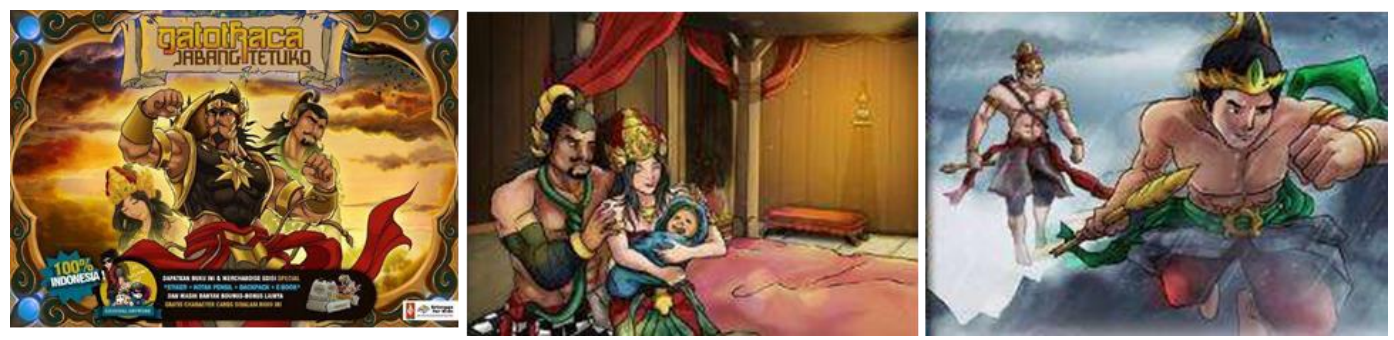

Gambar 2. Buku cerita dengan pendekatan bahasa rupa 'NPM'

Sumber: screenshot karya mahasiswa DKV UDINUS

Kedua contoh di atas merupakan media komunikasi grafis yang dirancang secara estetis, namun secara visualisasi hanya menampilkan adegan seperti hasil jepretan kamera yang digambar dari satu arah, satu waktu, dan satu kejadian, sebagai ciri khas bahasa rupa 'NPM'. Merujuk pada teori Profesor Primadi Tabrani (2005), bahasa rupa fokus pada aspek 'storytelling' (bercerita) dibanding aspek estetis dan simbolis (Talani \& Piliang, 2019:64). Bahasa rupa terdiri dari wimba dan tata ungkapan. Wimba merupakan imaji atau gambar yang bersifat konkret (kasat mata), dibagi menjadi dua yaitu: isi wimba dan cara wimba. Isi wimba yaitu objek yang digambar, sedangkan cara wimba adalah cara menggambar objek. Tata ungkapan merupakan cara menyusun wimba sehingga bisa bercerita, jika berada dalam sebuah sebuah panel/frame disebut tata ungkapan dalam, sedangkan jika melibatkan peralihan ruang atau waktu disebut tata ungkapan luar.

Hingga saat ini penulis belum banyak menemukan buku cerita bergambar yang divisualisasikan dengan pendekatan RWD. Seharusnya, bahasa rupa RWD bisa dikembangkan dan diterapkan secara lebih luas sebagai sarana komunikasi grafis khususnya untuk melestarikan agar tidak hilang. Permasalahan ini menjadi peluang bagi pihak praktisi maupun akademisi untuk turut mengembangkan bahasa rupa RWD. Khususnya bagi mahasiswa jurusan Desain Komunikasi Visual (DKV) untuk mengeksplorasi bahasa rupa RWD dan kemungkinan dipadukan dengan bahasa rupa NPM sehingga semakin memperkaya perbendaharaan bahas 
rupa Indonesia. Hal ini juga menjadi ketertarikan penulis karena sebelumnya penulis pernah melakukan penelitian yang mengimplementasikan bahasa rupa 'NPM' maupun 'RWD'. Penelitian pertama yaitu transformasi bahasa rupa 'RWD' ke 'NPM' dalam perancangan desain karakter wayang kulit (Haryadi \& Khamadi, 2014). Penelitian kedua yaitu adaptasi bahasa rupa 'RWD' sebagai media bercerita gambar format 3D tentang sejarah Monumen Tugu Muda Semarang (Yanuarsari \& Haryadi, 2019).

\section{METODE PENELITIAN}

Penelitian ini menggunakan pendekatan kualitatif yang fokus mendalami permasalahan dalam dunia komunikasi grafis secara deskriptif dan mempelajari konsep-konsep komunikasi grafis saat ini yang mengarah pada buku cerita bergambar anak. Guna menunjang penelitian ini dilakukan pengumpulan data melalui observasi tentang beragam gaya buku cerita anak, studi literatur tentang bahasa rupa, serta dokumentasi beberapa karya tugas akhir mahasiswa. Penelitian ini dilakukan untuk menemukan konsep perpaduan bahasa rupa modern NPM dengan bahasa rupa tradisional RWD melalui studi kasus karya tugas akhir mahasiswa DKV Universitas Dian Nuswantoro (UDINUS) berwujud accordion book berjudul “ANDI dan BAHAYA GADGET” yang dirancang oleh Kevin Abiwardani.

Pemilihan karya ini karena konsep unik yang digunakan untuk menyajikan cerita, yaitu membuat cerita bergambar tanpa teks dengan konsep memanjang seperti relief candi Borobudur serta tanpa batas frame sehingga menyambung tanpa putus dari awal cerita hingga akhir. Karya ini dibuat dengan teknik manual drawing, kemudian discan dan dicetak pada kertas foto lalu dibuat menyambung satu per satu hingga menjadi cerita utuh. Upaya penemuan konsep perpaduan kedua bahasa rupa dalam karya tersebut diawali dengan mengamati cerita dalam bentuk bahasa rupa dari halaman awal hingga akhir, lalu membagi cerita panjang menjadi beberapa fragmen cerita yang lebih kecil, dilanjutkan dengan pencarian 
makna tiap fragmen cerita menggunakan teori Wimba (isi dan cara wimba) serta Tata Ungkapan (dalam dan luar). Tahap terakhir yakni mengambil kesimpulan menyeluruh berdasar pada analisis yang telah dilakukan.

\section{ANALISIS DAN PEMBAHASAN}

Visualisasi dari cerita bergambar ini menggabungkan bahasa rupa NPM dan RWD. Tokoh yang ditampilkan dalam cerita yaitu: Andi (tokoh utama), peri, ayah-ibu, serta teman bermain Andi. Karya ini terdiri dari 10 lipatan termasuk sampul. Untuk memudahkan dalam memahami cerita, penulis membaginya menjadi 5 (lima) segmen cerita berdasarkan kesamaan waktu dan tempat kejadian. Berikut analisis tiap segmen menggunakan teori bahasa rupa tentang wimba dan tata ungkapan.

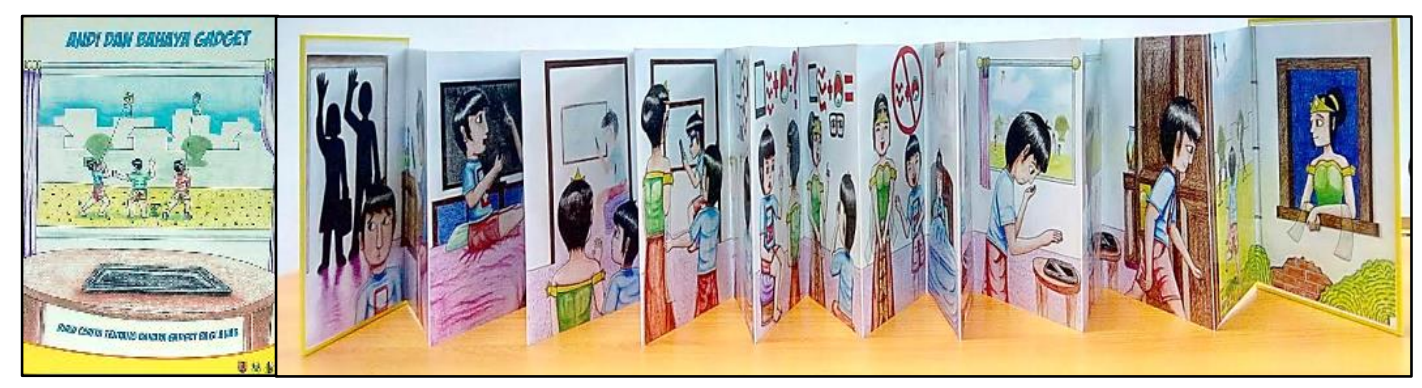

Gambar 3. Accordion book karya tugas akhir mahasiswa DKV

Sumber: dokumentasi pribadi

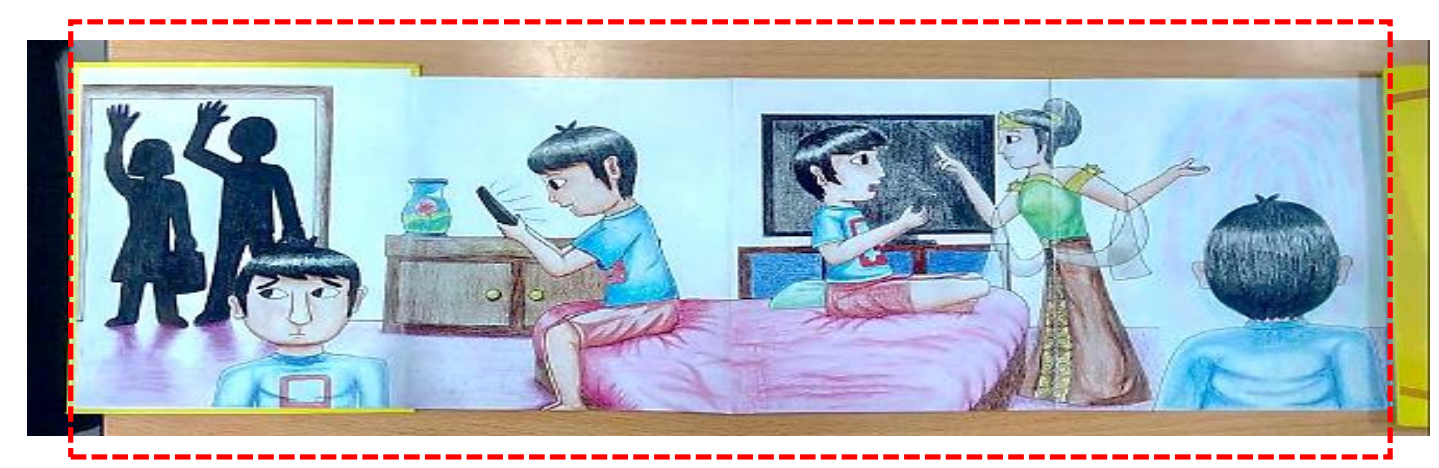

Gambar 4. Segmen 1: awal cerita (introduction)

Sumber: dokumentasi pribadi 
Segmen 1 memuat wimba Andi, peri, ayah-ibu, serta interior kamar tidur (Gambar 4). Andi digambar empat kali dengan empat sudut pandang yakni Medium Close Up (MCU) tampak depan, Medium Long Shot (MLS) tampak samping kiri, Long Shot (LS) tampak samping kanan, dan MCU tampak belakang. Ini berarti Andi menjadi tokoh utama. Peri digambar LS tampak samping kiri full. Ayah-ibu digambar LS tampak depan siluet full sebagai tokoh figuran. Interior kamar divisualisasikan dengan teknik $\mathrm{x}$-ray seolah tidak berdinding. Semua digambar dengan sistem NPM menggunakan prinsip perspektif semakin jauh ukurannya semakin kecil dan sebaliknya. Dari aspek ruang, segmen ini menggunakan tata ungkapan dalam dengan teknik 'digeser' (kiri ke kanan), sedangkan aspek waktu menggunakan urutan kejadian kilas maju. Sehingga, segmen 1 memuat cerita Andi yang sendirian ditinggal oleh orang tuanya yang bekerja merasa kesepian. Untuk mengisi waktu luangnya, Andi bermain smartphone cukup lama hingga akhirnya dia kaget dengan kedatangan peri yang bermaksud menyampaikan sesuatu terkait aktivitas yang baru saja Andi lakukan. Andi menjadi penasaran dan diperlihatkan sesuatu yang bersifat misteri.

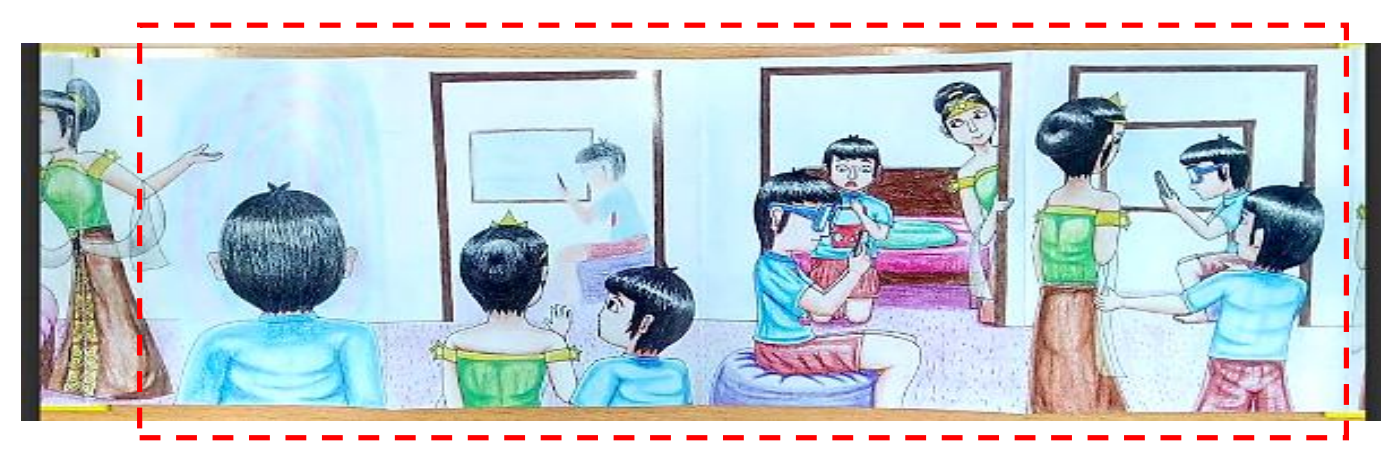

Gambar 5. Segmen 2: awal permasalahan cerita

Sumber: dokumentasi pribadi

Segmen 2 berisi wimba Andi, peri, dan interior kamar (Gambar 5). Andi digambar tujuh kali dengan berbagai angle dan ukuran, di sini masih menjadi tokoh utama. Peri digambar 4 kali dengan berbagai angle dan ukuran. Interior 
kamar masih digambar dengan teknik x-ray. Untuk ukuran tiap objek masih menggunakan sistem NPM khususnya perspektif. Peralihan dari segmen 1 ke segmen 2 menggunakan tata ungkapan luar untuk lokasi dan waktu cerita yang digambar dengan teknik 'alih pengambilan' dan 'alih ruang dan waktu', yaitu dari kiri ke kanan, dari belakang ke depan, depan ke belakang, serta kejadian konkret ke imajinasi/abstrak. Visualisasi tokoh Andi 'imajiner' berkacamata yang digambar sebanyak tiga kali dengan pose yang sama merupakan tata ungkapan dalam 'penting', yang mana menjadi point of interest dalam segmen ini. Sehingga, segmen 2 bercerita tentang peri yang menasihati Andi dengan membawanya masuk ke dalam dunia imajinasi. Di dalam dunia tersebut, muncul tokoh Andi 'imajiner'. Aktivitas Andi 'imajiner' membuat Andi kaget dan menjadi takut karena di dunia imajinasi dia menggunakan kacamata akibat terlalu lama dan asyik bermain smartphone. Ketakutan itu tampak pada perulangan adegan saat Andi melihat dirinya sendiri di dunia imajinasi.

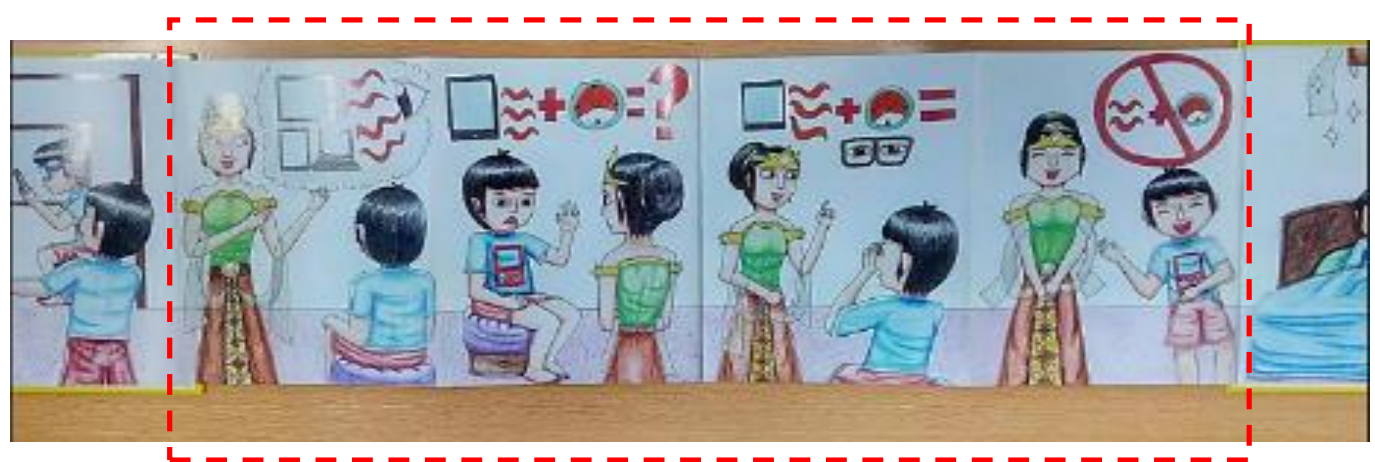

Gambar 6. Segmen 3: konflik cerita

Sumber: dokumentasi pribadi

Segmen 3 berisi wimba yang hampir sama dengan segmen 2 yaitu tokoh Andi, peri, dan infografis gambar gadget, jam, mata, serta kacamata (Gambar 6). Andi dan peri sama-sama digambar 4 kali dengan angle MLS. Adegan percakapan antara Andi dengan peri dilihat sebagai interaksi melalui 'arah lihat berhadapan' yang saling bergantian. Percakapan tidak menggunakan tulisan, tetapi melalui 
infografis yang ditampilkan dengan penggambaran stilasi di sisi atas. Latar cerita yang hanya terjadi di satu tempat menggunakan tata ungkapan dalam 'Penting' melalui 'frekuensi penampilan' sebagaimana teknik ini digunakan pada segmen 2. Cerita ini harus dilihat dengan kombinasi antara 'arah lihat kiri-kanan' dengan 'arah lihat bawah-atas'. Sehingga, segmen 3 ini bercerita tentang peri yang menasihati Andi dan memberi tahu bahwa anak kecil seusianya saat ini sering bermain gadget seperti smartphone, laptop, dan tablet dalam durasi waktu yang sangat lama sehingga bisa membuat mata mengalami gangguan dan akibatnya harus memakai kaca mata. Peri berhasil membuat Andi mengerti bahaya gadget jika digunakan secara berlebihan dan keduanya senang jika audiens tidak melakukan hal tersebut.

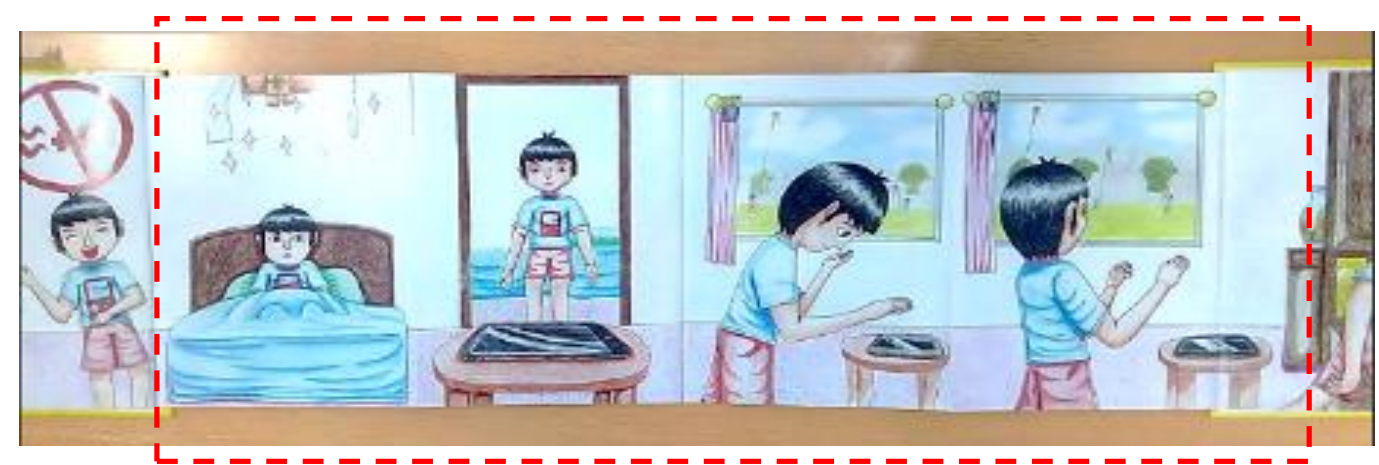

Gambar 7. Segmen 4: solusi penyelesaian masalah

Sumber: dokumentasi pribadi

Segmen 4 berbeda dengan segmen-segmen sebelumnya, yakni hanya menampilkan wimba tokoh Andi dengan latar kamar tidur, ruang tamu, dan penampang lapangan bermain beserta properti masing-masing (Gambar 7). Dari kiri ke kanan, Andi digambar dengan angle LS menghadap depan dan MLS menghadap samping kanan. Prinsip perspektif masih digunakan di sini. Peralihan segmen 3 ke segmen 4 menampilkan terjadinya lapisan latar dan waktu yang berbeda yaitu dari dunia mimpi/imajiner ke dunia realita dalam cerita. Di bagian tengah ke kanan, terdapat dua latar yang digambarkan dengan prinsip 'depth of 
field' yakni ruang tamu sebagai latar depan digambar dengan jelas dan lapangan bermain di luar rumah sebagai latar belakang digambar buram/blur. Latar depan menjadi cerita utama, sekaligus menjadi penanda adanya transisi latar di cerita selanjutnya. Sehingga, segmen 4 bercerita Andi yang terbangun dan kaget dengan mimpinya bertemu peri. Andi berjalan keluar kamar dan melihat tablet PC tergeletak di atas kursi. Saat hendak mengambilnya, Andi teringat mimpinya tentang bahaya bermain gadget yang bisa merusak mata. Andi tidak jadi mengambilnya dan justru melihat ke arah jendela. Di kejauhan, tampak tampak teman-temannya sedang bermain layang-layang di lapangan sebelah rumah.

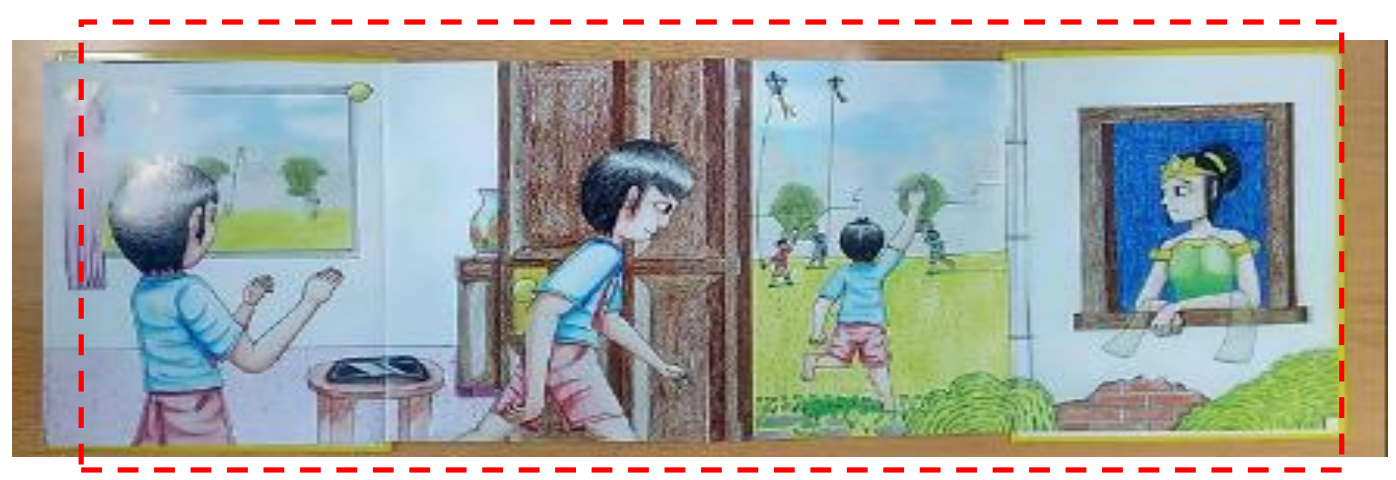

Gambar 8. Segmen 5: cerita penutup

Sumber: dokumentasi pribadi

Segmen ini merupakan segmen terakhir sekaligus menjadi solusi dari cerita yang diangkat (Gambar 8). Wimba yang terdapat dalam segmen ini yaitu tokoh Andi yang digambar dengan dua angle yaitu MLS (tampak samping kanan) dan LS (tampak belakang), peri digambar MLS tampak depan serong, serta tiga orang teman Andi (figuran) yang digambar Extreme Long Shot (ELS) hadap depan. Penggambaran segmen ini juga menerapkan prinsip perspektif. Lokasi cerita diungkapkan melalui 'sejumlah latar' yaitu ruang tamu di dalam rumah, depan rumah sebagai transisi latar, serta lapangan bermain di luar rumah. Perbedaan segmen ini dengan segmen-segmen sebelumnya yaitu arah lihat. Jika pada segmen 1 hingga 4 arah lihatnya dari kiri ke kanan, segmen 5 ini menggunakan 
arah lihat 'memusat' dengan prinsip ' cerita penting ada di tengah'. Poin utama dari segmen ini yaitu adegan di lapangan bermain. Sehingga, segmen 5 bercerita setelah Andi melihat teman-temannya dari balik jendela, Andi menuju ke luar rumah. Andi berlari sambil melambaikan tangan untuk ikut bergabung dengan teman-temannya yang sedang bermain layang-layang di lapangan dekat rumah. Dari bilik jendela lainnya, peri tampak tersenyum melihat Andi yang pada akhirnya memilih bermain dengan teman sebayanya alih-alih bermain tablet PC. Wajah Andi dan peri yang tersenyum serta ekspresi gembira teman Andi menjadi happy ending dari cerita ini.

Dari penjabaran wimba, cara wimba, serta tata ungkapan tiap segmen dalam cerita di atas, maka bisa disimpulkan cerita yang terkandung dalam karya mahasiswa dalam bentuk accordion book yaitu:

"Andi dalam kesehariannya selalu sendiri dan merasa kesepian, ditinggal oleh orang tuanya yang bekerja. Untuk mengisi waktu luangnya, Andi bermain smartphone cukup lama hingga akhirnya dia kaget dengan kedatangan peri yang bermaksud menyampaikan sesuatu terkait aktivitas yang baru saja dia lakukan. Andi menjadi penasaran dan diperlihatkan sesuatu yang bersifat misteri. Peri membawanya masuk ke dalam dunia imajinasi untuk memberi nasihat kepada Andi. Di dalam dunia tersebut, muncul tokoh Andi 'imajiner'. Aktivitas Andi 'imajiner' membuat Andi kaget dan menjadi takut karena di dunia imajinasi dia menggunakan kacamata akibat terlalu lama dan asyik bermain smartphone. Ketakutan itu tampak pada perulangan adegan saat Andi melihat dirinya sendiri di dunia imajinasi. Peri menasihati dan dan memberi tahu Andi bahwa anak kecil seusianya saat ini sering bermain gadget seperti smartphone, laptop, dan tablet PC dalam durasi waktu yang sangat lama sehingga bisa membuat mata mengalami gangguan dan akibatnya harus memakai kaca mata. Peri berhasil membuat Andi mengerti bahaya gadget jika digunakan secara berlebihan, dan keduanya senang jika pembaca tidak melakukan hal tersebut. Andi yang 
terbangun dan kaget dengan mimpinya bertemu peri. Andi berjalan keluar kamar dan melihat tablet PC tergeletak di atas kursi. Saat hendak mengambilnya, Andi teringat mimpinya tentang bahaya bermain gadget yang bisa merusak mata. Andi tidak jadi mengambilnya dan justru melihat ke arah jendela. Di kejauhan, tampak tampak teman-temannya sedang bermain layang-layang di lapangan sebelah rumah. Setelah Andi melihat teman-temannya dari balik jendela, Andi menuju ke luar rumah. Andi berlari sambil melambaikan tangan untuk ikut bergabung dengan teman-temannya yang sedang bermain layang-layang di lapangan dekat rumah. Dari bilik jendela lainnya, peri tampak tersenyum melihat Andi yang pada akhirnya memilih bermain dengan teman sebayanya alih-alih bermain tablet PC. Wajah Andi dan peri yang tersenyum serta ekspresi gembira teman Andi menjadi momen terindah dalam hidupnya."

\section{KESIMPULAN}

Eksplorasi bahasa rupa RWD dalam karya mahasiswa jurusan DKV berwujud accordion book termasuk hal yang baru dan belum banyak dilakukan, terutama masih mempertahankan media komunikasi grafis konvensional berwujud cetak yang saat ini mulai tergeser oleh media komunikasi grafis digital (online). Kreativitas ini menjadi solusi yang menarik sekaligus melestarikan bahasa rupa RWD sebagai bahasa rupa asli Indonesia, agar bisa bersanding dengan bahasa rupa NPM modern yang bersifat dominan. Penggabungan kedua bahasa rupa ini merupakan cara yang tepat agar masyarakat sebagai audiens atau 'pembaca' bisa menerima teknik visualisasi lainnya sehingga ke depan bisa dihasilkan karya komunikasi grafis yang dikemas secara kreatif dan variatif.

Studi analisis karya tugas akhir mahasiswa ini masih memiliki kekurangan terutama dalam pemaparan cara wimba dan jenis tata ungkapan yang hanya mempertimbangkan hasil pengamatan mandiri dari penulis, sehingga analisis cenderung kurang objektif. Hasil analisis akan lebih maksimal dan objektif jika 
melibatkan pengamat lain dalam membedah konsep cerita dari karya ini sehingga akan dihasilkan variasi konsep cerita. Hal ini bisa menjadi pertimbangan untuk penelitian selanjutnya khususnya yang fokus pada bahasa rupa RWD. Terlepas dari kekurangan tersebut, penelitian ini juga diharapkan bisa menjadi referensi bagi mahasiswa lainnya maupun praktisi untuk mencoba mengeksplorasi bahasabahasa rupa tradisional secara berani dan totalitas sebagai pilihan utama maupun alternatif dalam mengkomunikasikan sebuah gagasan kepada khalayak luas. Dengan demikian, teknik bahasa rupa tradisional yang dimiliki Indonesia tidak punah ditelan zaman.

\section{DAFTAR PUSTAKA}

Cahyana, Budi. 2019. Hari Buku Anak Sedunia: Dunia Buku Anak Terus Berkembang. Diakses dari: https://jogjapolitan.harianjogja.com/read/2019/04/02/510/982385/haribuku-anak-sedunia-dunia-buku-anak-terus-berkembang, pada: 16 juli 2019 pukul 12.15 wib

Hariyanto, Puguh. 2019. Era Informasi Teknologi, Media Massa dan Media Baru

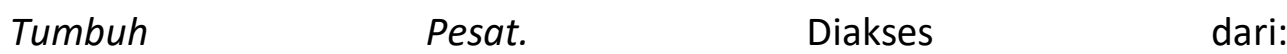
https://nasional.sindonews.com/read/1384726/144/era-informasiteknologi-media-massa-dan-media-baru-tumbuh-pesat-1551955471, pada: 16 Juli 2019 pukul 00.07 wib

Haryadi, Toto. \& Khamadi, Khamadi. 2014. Perancangan Model Wujud Visual Tokoh Pewayangan dalam Pembentukan Identitas dan Watak Tokoh sebagai Acuan Desain Karakter dalam Karya DKV. Jurnal Dekave, Vol. 7 No. 2, h 58-79.

Ika, Aprillia. 2018. Survei Nielsen: Media Digital dan Media Konvensional Saling Melengkapi. Diakses dari: 
https://ekonomi.kompas.com/read/2018/02/15/093533926/surveinielsen-media-digital-dan-media-konvensional-saling-melengkapi?page=all, pada: 16 Juli 2019 pukul 02.30 wib

Jackson, Tim. \& Shaw, David. 2009. Mastering Fashion Marketing. Basingstoke: Palgrave Macmillan

Kotler, Philip. \& Armstrong, Gary. 2001. Prinsip-Prinsip Pemasaran (jilid 2, edisi 8). Jakarta: Erlangga

Kotler, Philip., Kartajaya, Hermawan. \& Huan, Hooi Den. 2017. Marketing for Competitiveness: Asia yang Mendunia pada Era Konsumen Digital! (terjemahan). Yogyakarta: Bentang

Oka, Gde Putu Arya. 2017. Media dan Multimedia Pembelajaran. Yogyakarta: Deepublish

Tabrani, Primadi. 2005. Bahasa Rupa. Bandung: Kelir

Talani, Noval Sufriyanto \& Piliang, Yasraf Amir. 2019. Krisis Indonesia di Tahun 1997-1998 dalam Bahasa Rupa Kartun Editorial Surat Kabar Kompas dan Republika. Jurnal Demandia, Vol. 4 No.1, h 62-80.

Yanuarsari, Dzuha Hening. \& Haryadi, Toto. 2019. Adaptasi Difusi Inovasi dalam Media Edukasi Historikal Monumen Tugu Muda Semarang. Jurnal Audience, Vol. 2 No. 1, h 85-97. 